\title{
Effects of high-altitude reservoirs on the structure and function of lotic ecosystems: a case study in Italy
}

\author{
Antonio Petruzziello $\cdot$ Luca Bonacina $\cdot$ Francesca Marazzi $\cdot$ Silvia Zaupa $\cdot$ \\ Valeria Mezzanotte $\cdot$ Riccardo Fornaroli $($ i)
}

Received: 27 May 2020/Revised: 28 November 2020/ Accepted: 27 December 2020/Published online: 3 February 2021

(C) The Author(s) 2021

\begin{abstract}
Alpine and pre-alpine lotic ecosystems are often remote and not affected by humans, which makes them some of the world's most pristine ecosystems. However, their status is often altered by the presence of reservoirs that are built to fulfill agricultural needs and hydroelectric demands. These reservoirs also disrupt stream continuity and alter the magnitude, timing, and frequency of natural flows. The present work assessed how high-altitude reservoirs affect the riverine ecosystems focusing on the following: (i) the macroinvertebrate communities, (ii) the breakdown of organic matter, and (iii) the thermal regime. Stretches altered by high-altitude reservoirs had the best conditions for most macroinvertebrate families due to a more stable flow conditions. The breakdown rate of coarse particulate organic matter was not affected by high-altitude reservoirs but its availability was higher in altered compared to pristine stretches. The presence of hydroelectric power plants modified the stream thermal regime. Reservoirs mitigate the atmospheric influence on stream water temperature while run of the river plants strengthen
\end{abstract}

Handling editor: Andrew Dzialowski.

A. Petruzziello - L. Bonacina - F. Marazzi ·

S. Zaupa $\cdot$ V. Mezzanotte $\cdot$ R. Fornaroli $(\bowtie)$

Department of Earth and Environmental Sciences

(DISAT), University of Milano-Bicocca, Piazza della

Scienza 1, 20126 Milan, Italy

e-mail: riccardofornaroli@gmail.com it in the diverted stretches. Where both these alterations were present, the thermal regime of the stream was more similar to the natural ones compared to stretches subjected to only one kind of alteration. This research showed how river impoundment alters the structure of macroinvertebrate communities and the function of the downstream lotic ecosystems and can provide the basis to correctly guide management strategies for lotic ecosystems affected by hydrological alterations.

Keywords Bioassessment - Hydrology · Macroinvertebrates community · Leaf bag · Thermal regime

\section{Introduction}

Alpine and pre-alpine lotic ecosystems are often remote and not affected by human presence and activities, which makes them some of the world's most pristine ecosystems (Füreder et al., 2002; Hotaling et al., 2017). Moreover, due to significant habitat isolation and environmental heterogeneity, they show high levels of biodiversity and some of the species living there are endemic and have thus high naturalistic value (Muhlfeld et al., 2011; Jordan et al., 2016). The communities inhabiting alpine ecosystems are confined to high elevation sites due to temperature 
requirements. However, global warming is pushing them upslope toward mountaintops and shrinking their habitat (McGregor et al., 1995; Brown et al., 2007). Considering their importance and vulnerability, studying and protecting alpine lotic ecosystems is a priority.

The first reservoirs were built on alpine streams in the 19th century in order to fulfill agricultural needs and hydroelectricity demand. At that time, the attention was mainly focused on social-economic consequences and on the potential dangers to humans, while the environmental impacts were mainly unknown and thus ignored. Nowadays, it is well known that reservoirs disrupt the river continuity and produce hydrological alterations which can be defined as any anthropogenic disruption in the magnitude, timing, and frequency of natural flows (Zolezzi et al., 2009; Bocchiola, 2014). A common downstream effect is that the flood peak, and hence the frequency of overbank flooding, is reduced and sometimes displaced in time (Petts, 1984). In the upstream, sediment accumulates in the slow moving water of the reservoir, while the water released downstream has low concentrations of suspended solids (Anselmetti et al., 2007). This modification of the sediment cycling in the river leads to major erosion downstream. Williams \& Wolman (1984) concluded that 21 rivers in North America showed rapid riverbed erosion after reservoir construction. Reservoirs act as lake and the stored water can be affected by stratification in summer/ winter and destratification in spring/autumn. For that reason, the temperature of water released from the reservoir into the river depends on stratification/ destratification (Dickson et al., 2012) and on the level of the discharge. As an example, Wiejaczka et al. (2018) found that the presence of the CzorsztynSromowce Wyżne reservoir complex (Poland) decreased river water temperature in summer, winter, and spring (by $6.9,0.7$, and $7.9^{\circ} \mathrm{C}$, respectively), whereas in autumn, it had an opposite effect, raising it by $7.9^{\circ} \mathrm{C}$.

Reservoirs modify structural and functional characteristics of riverine ecosystems by altering the rate of degradation/transport of organic matter and the drift of organisms (Martínez et al., 2013). According to the Serial Discontinuity Concept (SDC, Ward \& Stanford, 1995; Stanford \& Ward, 2001), dams result in upstream-downstream shifts in biotic and abiotic patterns and processes; the direction and extent of the displacement depend on the variable of interest and are a function of dam position along the river continuum. The CPOM (Coarse Particulate Organic Matter)-to-FPOM (Fine Particulate Organic Matter) ratio declines naturally as the detritus is transported downstream (Fenoglio et al., 2015), but reservoirs greatly depress the ratio of coarse particulate to fine particulate organic matter (CPOM/FPOM) below the impoundment because the instream transport of detritus is blocked as highlighted by the SDC (Ward \& Stanford, 1995). However, the response of organic matter to impoundment is variable in the literature: a study concerning the Colorado River showed a suppression of CPOM below the impoundment with recovery beginning at $3 \mathrm{~km}$ (Voelz \& Ward, 1991). In contrast, the highest value of CPOM was found at the first site below the Dam in the Canning River (Australia), while it decreased sharply $5 \mathrm{~km}$ downstream (Storey et al., 1991). Moreover, CPOM was reduced with the increase of fine sediment in the river and this also affected the abundance of invertebrate shredders (Doretto et al., 2016). The CPOM/FPOM ratio is highly influenced by water flow: while FPOM is transported downstream regardless of flood magnitude, CPOM is more influenced by floods. The transport of CPOM downstream increases with increasing flow because the greater water strength drags branches trapped between rocks and removed from the trees.

The effect of impoundment on macroinvertebrate abundance and diversity is variable in the literature. Principe (2010) found that macroinvertebrate richness and diversity increased in an Argentine mountain river downstream from the dams, but there were no differences in macroinvertebrate density. In contrast, Martínez et al. (2013) found that the average number of macroinvertebrate taxa per sample was higher in upstream sites compared to downstream sites in five low-order streams in Northern Spain. The taxa richness of shredders, collector-gatherers and scrapers was lower in the streams downflow the dams than in the upflow streams. The Shannon diversity of the entire macroinvertebrate assemblage, EPT (Ephemeroptera, Plecoptera, Trichoptera) richness, and total macroinvertebrate density were all lower downstream (Martínez et al., 2013). These differences were likely related to the fact that freshwater systems were affected by multiple stressors and macroinvertebrates might be affected differently by these stressors. Ward \& Stanford (1995) reported that river regulation could 
reduce the biodiversity level due to the reduced transport of organic matter. Other studies showed that filter-feeders, such as Simuliidae (Diptera), and collector-gatherers were often abundant near dams with constant baseflow conditions where the availability of FPOM was larger (Jones, 2013). Due to the variability in the response of freshwater systems to the same stressors in different biogeographical areas, it is useful to develop specific studies for each area.

Alpine streams are characterized by low primary production because of the high water velocity, low solar incidence, and high bed instability, all of which limit the growth of phytoplankton, macroalgae, bryophytes, and angiosperms (Maiolini \& Bruno, 2008; Bo et al., 2015). In these conditions, the ecosystem is heterotrophic, and the food web is sustained by organic matter coming from the riparian zone, such as leaf litter. Leaf litter breakdown, which involves the release of soluble compounds the decomposition by microorganisms, and the feeding by benthic macroinvertebrates, is a key process linking nutrient cycling, energy transfer and trophic interactions (McArthur \& Barnes, 1988). For this reason, the measurement of leaf litter breakdown is a useful tool in alpine and pre-alpine stream assessments as it links the characteristics of riparian vegetation with the activity of microorganisms and invertebrates (Schmera et al., 2017). Moreover, leaf litter breakdown is affected by natural and human-induced variations of a wide range of environmental factors. In the last twenty years, many stream surveys (i.e., Danger \& Robson, 2004; Graça et al., 2015) and experiments used leaf breakdown rate as a direct measure of ecosystem functioning. Many of those studies focused on the degradation of leaves abscised during the autumn (McArthur \& Barnes, 1988; Albariño \& Balseiro, 2002) using artificial leaf bags (Braioni et al., 2001). In summer, most of the leaves fallen in the streams during autumn have already been degraded (Slade \& Riutta, 2012). However, some leaf input occurs all year-round, in particular beech leaves are always abundant in the ephemeral tributaries that are dry for most of the year. Leaves entering streams during summer months, when the allochthonous matter is scarce, may provide important energetic resources for lotic organisms. Despite its importance, this source of organic matter is less studied than others (Maloney \& Lamberti, 1995).

Aquatic ecosystems are vulnerable to climate change due to the close links among climate, water availability, biological communities, and physical and chemical properties of stream water (Null et al., 2013; Hotaling et al., 2017). A continuously heating atmosphere can absorb more water vapor and can therefore offer a greater potential for heavy rainfall (Allan, 2012). Furthermore, due to the increase of temperature, rainfall will occur in the form of rain rather than of snow, especially in spring and autumn in the alpine and pre-alpine areas and in summer at higher altitudes, so the frequency and intensity of medium and large flood events are expected to increase, as well as the occurring of floods in spring and late autumn (Viganò et al., 2015). At the same time, due to the increase of hot and dry summer periods, low flow periods will occur more frequently, particularly at the end of summer (Piano et al., 2019). In this scenario, the increasing temperature in the atmosphere could lead to an increase in water temperature that could modify the ecological dynamics (Hette-Tronquart et al., 2013; Doretto et al., 2020) and increase the risks of pathogen transmission, especially among fish (Carraro et al., 2017). It is therefore important to assess the influence of high-altitude reservoirs on the structure and function of alpine lotic ecosystems, in order to assess and disentangle the effects of different water management actions and climate change scenarios.

The present study used detailed monitoring to assess the influence of high-altitude reservoirs on riverine ecosystems focusing on the alterations of: (i) the macroinvertebrate communities, (ii) the organic matter breakdown processes, and (iii) the thermal regime.

For the macroinvertebrate communities, we tested the following hypotheses: $\left(\mathrm{HM}_{1}\right)$ there are structural differences among the communities inhabiting the pristine stretch and the stretch altered by high-altitude dams while, downflow the confluence, the communities show an intermediate composition; $\left(\mathrm{HM}_{2}\right)$ there are families associated with the three considered stream stretches, representative of different alterations.

For the organic matter breakdown processes, the tested hypotheses were as follows: $\left(\mathrm{HO}_{1}\right)$ the summer breakdown rates decrease with increasing percentage of catchment drained by high-altitude reservoirs, due to the less intense mechanical degradation; $\left(\mathrm{HO}_{2}\right)$ coarse mesh leaf bags (accessible to invertebrates) show higher degradation rates than fine mesh bags (excluding invertebrates); $\left(\mathrm{HO}_{3}\right)$ both fallen and 
manually detached leaves are used as food sources for macroinvertebrates.

In the end, for the water thermal regime, the tested hypotheses were as follows: ( $\left.\mathrm{HT}_{1}\right)$ water temperature in the pristine stretch is higher than in the stretch altered by high-altitude dams in summer and lower in winter while it is intermediate in the stretch downflow the confluence; $\left(\mathrm{HT}_{2}\right)$ in summer, daily water temperature variation in the pristine stretch is higher than in the altered stretch; $\left(\mathrm{HT}_{3}\right)$ daily water temperature variations below the confluence are bigger in the site affected by the run of the river power plant and such variations are similar to the ones observed in the pristine stretch.

\section{Material and methods}

Study area

The study was carried out in the alpine valleys of Goglio stream in northern Italy (Fig. 1). Sanguigno is the main left tributary of Goglio. The two streams were selected because they mainly differ for the presence of high-altitude reservoirs. Goglio is characterized by the presence of five high-altitude reservoirs that regulate the flow regime (sites G1 and G2, upper Goglio), while the flow regime of Sanguigno is considered pristine (sites S1 and S2). That's why in this study Sanguigno was used as the reference system. High-altitude reservoirs are used only for hydroelectrical purposes, so they release only a minimum environmental flow into the Goglio stream. The flow discharge in Goglio is stable during the year, apart from the flood events caused by abundant precipitations. There are some small tributaries of Goglio that are not influenced by the high-altitude reservoirs but

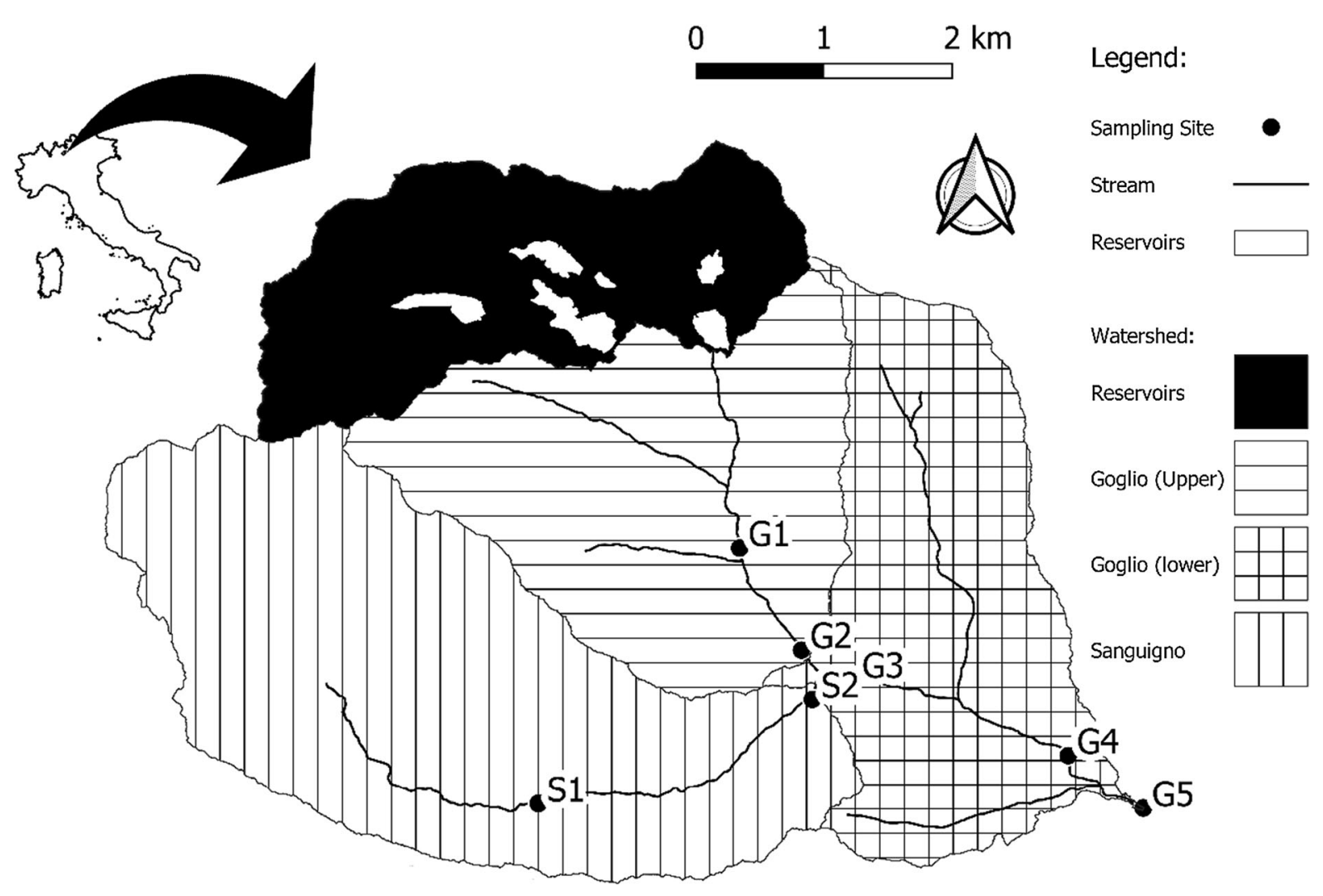

Fig. 1 Map of the study area with the location of sampling sites (G1, G2, G3, G4, G5, S1, and S2) and the representation of subwatershed for Goglio (G) and Sanguigno (S) streams with the indication of the watershed area drained by the high-altitude reservoirs 
all of them flow into Goglio downstream G1 site. Other anthropogenic activities in both watersheds are restricted to hikers and free-ranging livestock grazing, which makes them good reference systems. Downflow the confluence of Goglio and Sanguigno (sites G3, G4 and G5, lower Goglio), the anthropogenic activities in the watershed become more important with the presence of urban settlements and Run Of River hydroelectric power plants (ROR).

All the studied sites are located below the tree line, with an elevation ranging between 600 and 1,400 m above sea level (a.s.l.). Table 1 summarizes geographical information and watershed characteristics for each of them.

Sanguigno stream originates at 2,200 $\mathrm{m}$ a.s.1.. For a first stretch, it flows on a territory mainly covered by natural meadows. Then it flows for a short stretch (2-3 $\mathrm{km}$ ) on a flat plain with poor riparian vegetation characterized by alders, pines and other firs. Lastly, due to the sudden increase of the slope, it presents waterfalls and pools till the point of confluence with Goglio at an altitude of $940 \mathrm{~m}$ after $7 \mathrm{~km}$. This portion of the territory is covered by a mixed forest (mostly beeches but also alders, firs, birches, and ash trees).

Goglio stream originates at $1,950 \mathrm{~m}$ a.s.l. from artificial reservoirs: Cernello, Aviasco, Campelli, Sucotto, and Nero. At that altitude, due to the high slope, the stream presents waterfalls and pools and flows across a territory characterized by lithoid outcrops and permanent meadows. With decreasing altitude, a mixed forest (mostly beeches but also alders, firs, and ash trees) appears. Goglio flows in the
Serio River $3 \mathrm{~km}$ after the confluence with Sanguigno. The substratum varies from sand to bedrock including all the intermediate substrate classes without relevant differences among stream reaches. Coarse classes are more represented while instream vegetation is made of bryophytes.

Physical, chemical, and GIS analyses

In all the sampling sites, dissolved oxygen, electric conductivity (COND), and percent saturation of dissolved oxygen (DO_PERC) were measured on field by a multiparametric probe (HACH-Lange OD30). Water velocity and water depth were measured by a HACH-FH950 portable flowmeter. Water velocity was measured at $40 \%$ of the depth in order to obtain the mean velocity of the water column in the sampling point. Cross-sectional profiles were then used to calculate discharges. Analyses of $\mathrm{pH}$, chemical oxygen demand (COD), total phosphorus ( $\mathrm{P}_{-} \mathrm{TOT}$ ), total nitrogen ( $\mathrm{N}_{-} \mathrm{TOT}$ ), and ammonium $\left(\mathrm{N}_{-} \mathrm{NH}_{4}\right)$ in the water were carried out in laboratory according to standard methods (APHA/AWWA/WEF, 2012).

QGIS 2.18.9 (QGIS Development Team, 2018) software was used to determine the relative proportion of land use within the study area, while GRASS GIS 7.4.1 (GRASS Development Team, 2018) and the "watershed tool" were used to determine the watershed of each basin. Basin maps were intersected with the DUSAF 4.0 map (land cover dataset updated at 2012) of the Lombardy region.
Table 1 Geographical information, main channel, and watershed characteristics for each studied site

For each stream stretch, the main anthropic pressures are reported

\begin{tabular}{|c|c|c|c|c|c|c|c|}
\hline \multirow{3}{*}{$\begin{array}{l}\text { Stream stretch } \\
\text { Main impact sources } \\
\text { Site }\end{array}$} & \multirow{2}{*}{\multicolumn{2}{|c|}{$\frac{\text { Upper Goglio }}{\text { High-altitude dams }}$}} & \multirow{2}{*}{\multicolumn{2}{|c|}{$\frac{\text { Sanguigno }}{\text { Null }}$}} & \multirow{2}{*}{\multicolumn{3}{|c|}{$\begin{array}{l}\text { Lower Goglio } \\
\text { High-altitude dams } \\
\text { Run of river plant } \\
\text { Urban settlements }\end{array}$}} \\
\hline & & & & & & & \\
\hline & G1 & $\mathrm{G} 2$ & $\mathrm{~S} 1$ & $\mathrm{~S} 2$ & G3 & G4 & G5 \\
\hline Altitude (m a.s.1.) & 1,128 & 977 & 1,395 & 979 & 932 & 718 & 633 \\
\hline Distance from source $(\mathrm{m})$ & 1,540 & 2,620 & 4,290 & 6,970 & 3,140 & 5,020 & 5,850 \\
\hline Stream width (m) & 6.3 & 7.1 & 7.2 & 2.4 & 4.6 & 6.7 & 16.7 \\
\hline Stream slope $\%$ & 53.4 & 14.0 & 16.4 & 15.5 & 8.7 & 11.4 & 10.2 \\
\hline Watershed area $\left(\mathrm{km}^{2}\right)$ & 8.1 & 13.6 & 7.7 & 11.5 & 25.4 & 31.0 & 32.2 \\
\hline Residual basin (\%) & 26.9 & 56.2 & 100.0 & 100.0 & 76.4 & 80.7 & 81.4 \\
\hline Natural (\%) & 95.4 & 95.2 & 100.0 & 98.3 & 79.5 & 73.9 & 83.0 \\
\hline Agricultural (\%) & 4.5 & 4.7 & 0.0 & 0.7 & 16.0 & 22.6 & 9.1 \\
\hline Urban (\%) & 0.0 & 0.2 & 0.0 & 0.0 & 4.6 & 3.6 & 7.9 \\
\hline
\end{tabular}


In order to get a continuous measurement of water temperature, we placed data loggers (iButton) at each site with a measurement range from $-5^{\circ} \mathrm{C}$ to $+26^{\circ} \mathrm{C}$ and an accuracy of $0.125^{\circ} \mathrm{C}$, and $\operatorname{loggers}$ with a measurement range from $-40^{\circ} \mathrm{C}$ to $+85^{\circ} \mathrm{C}$ and an accuracy of $0.0625^{\circ} \mathrm{C}$. Sensors were set with 1 -Wire software in order to get data in every 10,30 , and 60 min. A one-minute resolution dataset was obtained by the linear interpolation of temperature data within $\mathrm{R}$ software.

Macroinvertebrate community assessment

Macroinvertebrates were collected five times between summer 2017 and winter 2018 with a Surber net $(0.10$ $\mathrm{m}^{2}, 500 \mu \mathrm{m}$ mesh) by a standardized multi-habitat sampling procedure (Barbour et al., 1999; AQEM Consortium, 2002; Hering et al., 2004). Ten replicated samples were collected from different microhabitats according to their relative coverage in the examined site (only those with at least $10 \%$ of coverage were considered) and then merged in the field and stored in $96 \%$ ethanol. In the laboratory, taxa were identified at family level according to standard keys and the abundance of individuals of each taxon was reported.

\section{Leaf bag experiments set-up}

Two separate experiments were carried out, one in summer and one in winter, in order to evaluate if the degradation of CPOM during summer was influenced by the presence of high-altitude dams and if the degradation rates of fallen and detached leaves during winter were different. We used fallen beech leaves to prepare leaf bags during the summer experiment, while we used both fallen and manually detached beech leaves during the winter experiment. A total of 126 artificial leaf bags were placed in the study sites in summer and 24 leaf bags in winter. The main focus of the summer experiment was to assess the CPOM degradation along a gradient of alteration due to highaltitude reservoirs (residual basin of the sampling sites) while the winter experiment aimed to compare the degradation rate of fallen and manually detached leaves that are more commonly used in leaf bag studies (Boulton \& Boon, 1991). The leaf bags used in the summer experiment were prepared by using fallen beech leaves (Fagus sylvatica L.) collected in the study area. Only intact leaves were used for both the experiments. Leaves were brought to the laboratory shortly after collection and were dried at room temperature for 30 days. Five replicates were also dried for $24 \mathrm{~h}$ at $105^{\circ} \mathrm{C}$ to obtain standardized moisture contents (Cabrini et al., 2013). Afterwards, we used the weight reduction obtained for leaves dried at $105^{\circ} \mathrm{C}$ to calculate the dry weight of all the prepared leaf bags.

Leaves were placed in two kinds of synthetic net bags $20 \times 20 \mathrm{~cm}$ : one with $0.5 \mathrm{~mm}$ and the other with $5 \mathrm{~mm}$ mesh sizes (Nanda et al., 2009; Wang et al., 2010). Each net bag was filled with about $3 \mathrm{~g}$ of leaves and identified by a unique number. In July, we placed in the riverbeds a total of 126 leaf bags following this scheme: in all the sites, we identified three habitats (riffle, pool, and glide) and in each of them, we placed 3 pairs of leaf bags ( 3 with coarse mesh +3 with fine mesh) for a total of 18 bags per site (Table 2). For the winter experiment, we placed the leaf bags only in two sites: the first was a pristine one, while the second one was the most impacted by the high-altitude reservoir (S2 and G1, respectively). In both sites, we placed in each habitat (riffle, pool, and glide) one pair of bags made with fallen leaves ( 1 with coarse mesh +1 with fine mesh) and one pair made with manually detached leaves ( 1 with coarse mesh +1 with fine mesh) for a total of 12 bags per site (Table 2).

All bags were tied with plastic strips to metal rods that were knocked into the sediment. Five bags were brought to the laboratory and used to quantify the mass of leaves lost during transport/manipulation operations. The summer leaf bags were collected after 40, 62 and 98 days. In each collection, six leaf bags were removed from each site, one pair for each habitat (riffle, pool and glide), and shortly after transferred to the laboratory. All the winter bags were collected after 140 days. In the laboratory, the leaves were washed and then dried for $24 \mathrm{~h}$ at $105{ }^{\circ} \mathrm{C}$ in order to determine the remaining mass (Spänhoff et al., 2007). The mass loss was calculated by the difference between the initial and the final dry mass of leaves and reported as $\%$ of initial mass.

Data analyses

Principal component analysis (PCA) was used to evaluate the correlations among physical, chemical, and geographical variables in all the samples of the dataset (Hotelling, 1933). PCA was conducted using 
Table 2 Schematic representation of leaf bags positioning in the two experiments

\begin{tabular}{llll}
\hline Summer-7 sites (fallen leaves) & \\
Riffle & 1 coarse +1 fine & 1 coarse +1 fine & 1 coarse +1 fine \\
Pool & 1 coarse +1 fine & 1 coarse +1 fine & 1 coarse +1 fine \\
Glide & 1 coarse +1 fine & 1 coarse +1 fine & 1 coarse +1 fine \\
Winter-2 sites & \\
Riffle & 1 coarse +1 fine (fallen leaves) & 1 coarse +1 fine (manually detached leaves) \\
Pool & 1 coarse +1 fine (fallen leaves) & 1 coarse +1 fine (manually detached leaves) \\
Glide & 1 coarse +1 fine (fallen leaves) & 1 coarse +1 fine (manually detached leaves) \\
\hline
\end{tabular}

the function prcomp from the "factoextra" package (Kassambara \& Mundt, 2017).

Non-metric multidimensional scaling (NMDS), a gradient analysis approach based on a distance or dissimilarity matrix, was used to visualize the differences in the taxonomic structure of the macroinvertebrate community among the studied stream stretches (Upper Goglio, Lower Goglio, Sanguigno) defined $a$ priori (Clarke \& Ainsworth, 1993) based on anthropogenic impacts. NMDS is an iterative procedure including several steps, using the function metaMDS from the "vegan" package (Oksanen et al., 2017) in R project software (R Core Team, 2019). It is based on Bray-Curtis dissimilarity distance evaluated using raw macroinvertebrate abundances, a non-Euclidean distance used to quantify the compositional dissimilarity between two different samples. Differences in the composition of communities among stream stretches were quantitatively explored, as well as temporal controls, testing also the additive effects of "sampling period" within a permutational multivariate analysis of variance (PERMANOVA) via the adonis function within the "vegan" package. To determine the most sensitive taxa to the different groups of impact, similarity percentage (SIMPER) analysis was implemented using the stream stretch as a primary factor and the simper function. Its significance was tested using 999 permutations within the "vegan" software package and abundance data were $\log _{10}(x+$ 1) transformed.

As many of the leaf bags used for the summer experiment were not recovered during the three surveys (31\% after 40 days, $45 \%$ after 62 days, and $60 \%$ after 90 days) because they had drifted downstream, a binary variable with value 0 or 1 for nonrecovered and recovered leaf bags, respectively, was associated with the data to reflect the probability of recovery. The probability of recovery of the leaf bags were examined using "generalized linear mixed-effect model" (GLMM) modeled with a Binomial distribution, which was performed by the glmer function in the "Ime4" package (Bates et al., 2015). The mesh size of each bag, the stay-in-place time, and the percent residual basin were used as fixed effects while sites and habitats within sites were used as random effects on intercept accounting for any lack of spatial independence between samples. The dispersion_glmer function within the "blmeco" package (Korner-Nievergelt et al., 2015) was used to ensure that GLMM was not under- or overdispersed. To validate the assumptions of GLMM, simulated residuals were plotted using the simulateResiduals function in the "DHARMa" package (Hartig, 2019). Remaining masses from both experiments were tested using linear mixed-effect models (LMM) by the lmer function in the "Ime4" package. The percentage of remaining mass was square-root transformed to normalize the residuals and equalize variances. Mesh size, stay-in-place time, and percent residual basin were used as fixed effects while sites and habitats within sites were used as random effects on intercept for the summer experiment. For the winter experiment, only two sites were monitored, representative of Sanguigno and upper Goglio. The sites, the mesh size, and the leaf type were considered as fixed effects while habitats were used as random effects on intercept.

The dredge function within the "MuMIn" package (Bartoń, 2019) was then used to derive the optimal set of fixed effects tested within each LMM and GLMM. This function fits different models comprising all the combinations of fixed effects and ranks them by the Akaike Information Criterion corrected for small sample size (AICc). The most parsimonious model within 2 AICc units of the model exhibiting the lowest AICc value was selected as the "optimal" model. The explanatory power of the statistical models was 
derived from marginal pseudo $r$-squared values $\left(r^{2} m\right.$; see Nakagawa \& Schielzeth, 2013), which quantify the variance explained by the fixed effects and were obtained using the rsquared.glmm function in MuMIn. The significance of each optimal model was obtained via likelihood ratio tests (White et al., 2018).

Finally, we used analysis of variance (ANOVA) to test the differences in mean daily water temperatures and daily temperature variations among the stream stretches considering the summer (June, July, and August) and winter (December, January, and February) months. One-way ANOVA with Tukey's test for pairwise comparisons was also used to analyze the differences among stream stretches and seasons. We selected one site for each stream stretch for temperature comparisons, specifically, G2 as representative of Upper Goglio, S2 as representative of Sanguigno, G3 as representative of Lower Goglio without the effect of ROR plant (G3 is located only $200 \mathrm{~m}$ downstream the confluence between Upper Goglio and Sanguigno and the water diversion), and G4 as representative of Lower Goglio subjected to the effect of ROR plant (G4 is located almost $2 \mathrm{~km}$ downstream G3).

All statistical analyses were performed using $\mathrm{R}$ project software (R Core Team, 2019).

\section{Results}

Environmental variables

The results of PCA are shown in Fig. 2 for variables related to physical and chemical water characteristics and land use $(n=35)$. The total variance explained by the first two axes was $49.6 \%: 34.8 \%$ by the first principal component and $14.8 \%$ by the second one. The first principal component was positively correlated with watershed area, urban and agriculture coverage and water total nitrogen and negatively with natural land use and elevation. The second principal component was positively correlated with water conductivity and COD and negatively with percent residual basin, water temperature, flow, and oxygen saturation. The plots of the two first principal components show high orthogonality between the effects of high-altitude reservoirs, represented by the residual basin (2nd PC) and the effects of watershed area and land use modifications (1st PC).

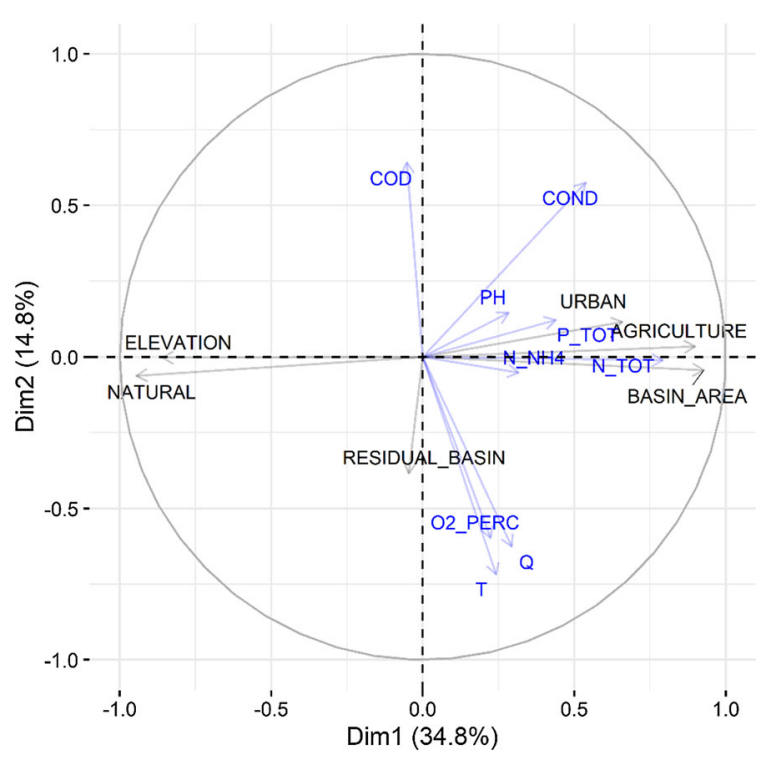

Fig. 2 Principal component analysis plot of the watershed characteristics (black text) of the seven sampling sites and of the water chemical characteristics (blue text) during the five samplings. Vector length and direction are proportional to its relationship with each axis

All the studied sites were characterized by a level of oxygenation close to saturation $(97.8 \pm 5.5$, mean \pm $\mathrm{SD})$ in all seasons. Nutrient concentrations were low $(<0.7 \mathrm{mg} / \mathrm{L})$ in all Sanguigno and Goglio sites; the only parameter that showed a clear spatial pattern was the total nitrogen whose concentration increased progressively up to a maximum $(1.1 \pm 0.2 \mathrm{mg} / \mathrm{l})$ in $\mathrm{G} 4$, then decreased considerably $(0.6 \pm 0.2 \mathrm{mg} / \mathrm{l})$. The influence of high-altitude reservoirs on Goglio basin was already reduced in G2. In fact, only $43.8 \%$ of the basin area is drained by the reservoirs. In G3, the influence of the reservoirs became marginal (23.6\%).

Similarity among macroinvertebrate communities

The NMDS plot of macroinvertebrate communities (Fig. 3) shows that the community inhabiting upper Goglio clustered separately from the communities inhabiting Sanguigno and lower Goglio supporting our $\mathrm{HM}_{1}$ hypothesis. Such results were confirmed by PERMANOVA that highlighted the significant differences among the communities of the three stream stretches $(F=1.64, P$-value $=0.018)$. SIMPER analysis highlighted that the densities of some macroinvertebrate families were significantly different in the three cases and that differences between 


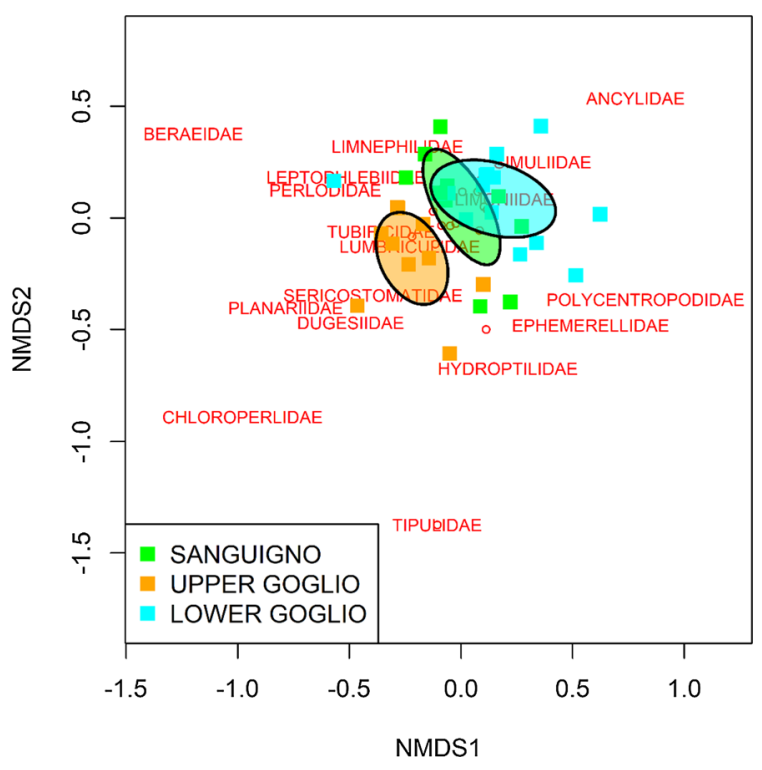

Fig. 3 Non-metric multidimensional scaling (NMDS) ordination plot for aquatic macroinvertebrate communities where the a-priori identified stream stretches are colored. Green denotes the communities that belong to Sanguigno stream $(n=10)$, orange and cyan denote, respectively, the communities that belong to upper $(n=10)$ and lower stretches of Goglio stream $(n=15)$. Shaded ellipses represent the $95 \%$ confidence interval surrounding the centroid of each stream stretch in the ordination space. Each square represents the overall macroinvertebrate community at each sampling. Macroinvertebrate families are positioned in the ordination space with red uppercase labels, as weighted averages. $3 \mathrm{D}$ stress $=0.18$

regulated (Upper Goglio) and non-regulated (Sanguigno) systems (Table 3) were particularly sharp, confirming our $\mathrm{HM}_{2}$ hypothesis. Eleven macroinvertebrate families, belonging to several taxonomic orders, displayed greater affinities for the regulated sites in upper Goglio than for the pristine sites in Sanguigno while no family showed the opposite pattern (Table 3). The comparison between upper Goglio and lower Goglio showed that some families had greater affinity for upper Goglio that is affected only by hydrological alterations, but none of them had greater affinity for lower Goglio that is affected by both hydrological and chemical alterations. Five families showed significantly different distributions between Sanguigno and lower Goglio: Perlidae and Heptageniidae were more abundant in Sanguigno while Leuctridae, Limoniidae, and Simuliidae had greater densities in lower Goglio.

\section{Leaf bags results}

The percent residual basin was included in the optimal model developed for the probability of recovery for the leaf bags of the summer experiment $(n=123)$ as well as the mesh size and the stay-in-place time (Table 4). The model partially supported our $\mathrm{HO}_{1}$ hypothesis. The probability of recovery decreased with increasing stay-in-place time and percent residual basin; moreover, coarse mesh bags always showed a lower probability of recovery (Fig. 4A) fully confirming our $\mathrm{HO}_{2}$ hypothesis. The remaining mass in the leaf bags of the summer experiment $(n=69)$ was significantly associated with the stay-in-place time and the mesh size, always lower in coarse mesh bags than in fine mesh ones, and decreased from a maximum of $96.9 \%$ in the first collection to a minimum of $5 \%$ in the last one (Fig. 4B). Those results suggest that our $\mathrm{HO}_{1}$ hypothesis should be partially revised: where the percent catchment area drained by high-altitude reservoirs was larger, the transport of CPOM increased but the breakdown rate did not. The remaining mass in the leaf bags of the winter experiment $(n=24)$ was significantly associated with the leaf type ("Fallen" or "Manually detached") and the mesh size. The remaining mass was lower for bags filled with falling leaves than for bags filled with leaves collected from the litter; this effect was greater in the coarse mesh bags than in the fine mesh ones (Fig. 4C), confirming that the access of macroinvertebrate is a significant factor in the degradation rates for the two types of leaves $\left(\mathrm{HO}_{3}\right)$.

\section{Analysis of water temperature}

Water temperature was measured continuously in order to detect temperature changes at very short time scale $(<1 \mathrm{~h})$. As it can be seen in Fig. 5, upper Goglio was colder in summer and warmer in winter than Sanguigno. One-way ANOVA $(P<0.001)$ and Tukey's test (always $P<0.001$ ) show a significant difference in the mean daily temperature (letters $\mathbf{c}$ and $\mathbf{d}$ and $\mathbf{f}$ and $\mathbf{g}$ in Fig. 6A) between the two sites, both in summer and winter. Moreover lower Goglio had an intermediate mean daily water temperature compared to upper Goglio and Sanguigno both in summer and winter as highlighted by Tukey's comparisons (letters a-b compared with $\mathbf{c}$ and $\mathbf{d}$ for summer and letter 
Table 3 SIMPER analysis of univariate responses of macroinvertebrates to environmental alterations
Codes for contrast are (UP)

Upper Goglio-High-

altitude dams, (SA)

Sanguigno-No impact,

(LG) Lower Goglio-Highaltitude dams/Run of river plant/Urban settlements.

Families that show

significant differences for at least one contrast are reported in bold. Average abundances for each sampled family are reported as $\log _{10}(x+1)$ transformed values

$N S$ non-significant

. $=p \leq 0.01 ; * p \leq 0.05$;

$* * p \leq 0.01 ; * * * p \leq 0.001$

\begin{tabular}{|c|c|c|c|c|c|c|}
\hline \multirow[t]{2}{*}{ Family } & \multicolumn{3}{|l|}{ Contrast } & \multirow{2}{*}{$\begin{array}{l}\text { Average } \\
\text { UG }\end{array}$} & \multirow{2}{*}{$\begin{array}{l}\text { Average } \\
\text { SA }\end{array}$} & \multirow{2}{*}{$\begin{array}{l}\text { Average } \\
\text { LG }\end{array}$} \\
\hline & UG-SA & UG-LG & LG-SA & & & \\
\hline Chloroperlidae & $*$ & NS & NS & 0.14 & 0.00 & 0.00 \\
\hline Leuctridae & NS & NS & $*$ & 1.26 & 1.36 & 1.77 \\
\hline Perlidae & NS & NS & $*$ & 0.66 & 0.61 & 0.33 \\
\hline Perlodidae & NS & . & NS & 0.46 & 0.16 & 0.14 \\
\hline Nemouridae & NS & NS & NS & 1.83 & 1.19 & 1.29 \\
\hline Baetidae & NS & NS & NS & 2.17 & 2.18 & 2.18 \\
\hline Ephemerellidae & NS & NS & NS & 0.14 & 0.40 & 0.34 \\
\hline Heptageniidae & NS & NS & . & 1.99 & 2.27 & 1.85 \\
\hline Leptophlebiidae & NS & NS & NS & 0.34 & 0.15 & 0.11 \\
\hline Beraeidae & NS & NS & NS & 0.00 & 0.00 & 0.05 \\
\hline Hydropsychidae & NS & NS & NS & 1.61 & 1.26 & 1.23 \\
\hline Hydroptilidae & $* *$ & NS & NS & 0.03 & 0.00 & 0.00 \\
\hline Limnephilidae & NS & NS & NS & 0.37 & 0.45 & 0.35 \\
\hline Odontoceridae & $*$ & NS & NS & 0.03 & 0.00 & 0.00 \\
\hline Philipotamidae & NS & NS & NS & 0.59 & 0.48 & 0.59 \\
\hline Polycentropodidae & NS & NS & NS & 0.00 & 0.00 & 0.11 \\
\hline Rhyacophilidae & * & NS & NS & 1.18 & 0.64 & 0.78 \\
\hline Sericostomatidae & $* * *$ & $* *$ & NS & 0.41 & 0.00 & 0.40 \\
\hline Elmidae & NS & NS & NS & 1.81 & 1.25 & 1.30 \\
\hline Hydraenidae & NS & NS & NS & 0.94 & 0.57 & 0.70 \\
\hline Athericidae & NS & $*$ & NS & 1.22 & 0.69 & 0.59 \\
\hline Blephariceridae & NS & NS & NS & 0.24 & 0.28 & 0.28 \\
\hline Chironomidae & NS & NS & NS & 1.43 & 1.04 & 1.53 \\
\hline Limoniidae & NS & NS & * & 0.57 & 0.55 & 1.01 \\
\hline Psychodidae & NS & NS & NS & 0.06 & 0.00 & 0.13 \\
\hline Simuliidae & NS & NS & * & 0.58 & 0.44 & 1.22 \\
\hline Tipulidae & * & NS & NS & 0.03 & 0.00 & 0.00 \\
\hline Scirtidae & $* *$ & * & NS & 0.74 & 0.14 & 0.21 \\
\hline Ancylidae & NS & NS & NS & 0.00 & 0.00 & 0.15 \\
\hline Planariidae & $* * *$ & $* *$ & NS & 0.58 & 0.00 & 0.00 \\
\hline Dugesiidae & $* * *$ & NS & NS & 0.03 & 0.00 & 0.00 \\
\hline Tubificidae & * & NS & NS & 0.05 & 0.00 & 0.00 \\
\hline Lumbricidae & NS & NS & NS & 0.22 & 0.14 & 0.12 \\
\hline Lumbriculidae & $* *$ & * & NS & 0.78 & 0.04 & 0.31 \\
\hline
\end{tabular}

temperature variation during winter was observed among the three sites.

Daily water temperature variations during summer months in lower Goglio were larger than in the upper Goglio, especially in the site affected by the ROR power plant where the variations were similar to the ones observed in Sanguigno. This supports our $\mathrm{HT}_{3}$ hypothesis $(P<0.001$, letters $\mathbf{a}$ and $\mathbf{b}$ compared to $\mathbf{c}$, Fig. 6B). 
Table 4 GLMM and LMM outputs examining the response of the probability of recovery and the percent remaining mass to the mesh size, the stay-in-place time, and the residual basin for the summer experiment

\begin{tabular}{|c|c|c|c|c|c|}
\hline Experiment & Response & Fixed terms & $X^{2}$ & $P$-value & $r^{2} m$ \\
\hline \multirow[t]{2}{*}{ Summer } & Probability of recovery $(\%)$ & Mesh + time + residual Basin & 25.79 & $<0.001$ & 0.31 \\
\hline & Remaining mass $(\%)$ & Mesh + time & 19.91 & $<0.001$ & 0.19 \\
\hline Winter & Remaining mass $(\%)$ & Mesh + leaf type & 20.81 & $<0.001$ & 0.56 \\
\hline
\end{tabular}

LMM outputs examining the response of remaining mass to the mesh size and the leaf type for the winter experiment

The seasonal variability in Sanguigno and in lower Goglio was higher than in upper Goglio. In winter, the average temperature was $\approx 0^{\circ} \mathrm{C}$ in Sanguigno and $\approx$ $2.6^{\circ} \mathrm{C}$ in lower Goglio while the average temperature of upper Goglio was $\approx 4^{\circ} \mathrm{C}$; in summer, the average temperature was $\approx 13^{\circ} \mathrm{C}$ in Sanguigno and $\approx 12.6^{\circ} \mathrm{C}$ in lower Goglio while the average temperature of upper Goglio was $\approx 10.3^{\circ} \mathrm{C}$. Considering the extremes of the water temperature range, the data show that during winter Sanguigno reached also negative values $\left(-0.72^{\circ} \mathrm{C}\right.$ in site SAN1), lower Goglio got to $0.89^{\circ} \mathrm{C}$ (in site G5) while upper Goglio achieved only $1.25^{\circ} \mathrm{C}$ (in site G1); in summer, Sanguigno reached $17.05^{\circ} \mathrm{C}$ (in site SAN2), lower Goglio got to $15.09^{\circ} \mathrm{C}$ (in site G4) while upper Goglio achieved only $12.30^{\circ} \mathrm{C}$ (in site G2). Obviously, the spring and autumn data of water temperature had intermediate values (either in the average and in the extremes) compared to the rest of the year.

\section{Discussion}

Environmental variables

The results of physical and chemical analyses show that the studied streams were characterized by a level of oxygenation close to saturation and by low concentrations of nutrients both in winter and in summer. The increase of the concentrations of total nitrogen and other parameters (P_TOT and N_NH 4 ) between G3 and G4 was due to the urban settlement of Valgoglio, while the decrease of nutrient concentrations in G5 was due to the dilution caused by the input of water coming from the high-altitude reservoirs, which passes through the Aviasco Hydroelectric plant and is finally released by the ROR hydroelectric plant located upstream G5. The increase of total nitrogen and water flow between S1 and S2 was due to natural inputs. There is no evidence of the effects of the highaltitude reservoirs on water chemistry and this is related to the very high location of the dams within the river network (Stanford \& Ward, 2001) but also to the absence of other anthropogenic impact except for the urban settlement downflow the dam and the main tributary.

\section{Macroinvertebrate community}

The analysis of macroinvertebrate samples shows that the presence of high-altitude reservoirs changed the structure of the macroinvertebrate community. Due to the decrease of the influence of the high-altitude reservoirs, and to the confluence of Sanguigno, the communities inhabiting lower Goglio showed a high similarity with the one inhabiting Sanguigno, fully supporting our $\mathrm{HM}_{1}$ hypothesis and in agreement with the predictions from the Serial Discontinuity Concept (Stanford \& Ward, 2001). In fact, only the densities of five families differed significantly between them. An interesting finding that emerged from the survey is that 11 macroinvertebrate families, spanning across several taxonomic orders, displayed greater affinities for the regulated sites in upper Goglio than for the pristine sites in Sanguigno while no family showed the opposite pattern. Below high-altitude reservoirs, the flow regime was more stable and the flood events dampened, creating more favorable conditions for the establishment of some families that were not present in the pristine sites.

The effects of stream regulation on mayflies are well documented in the literature (Brittain \& Saltveit, 1989; Mantel et al., 2010). Mantel et al. (2010) found an increase in some taxa (Baetidae, Caenidae) and a decrease in others (Teloganodidae and Heptageniidae) below dams. Similar changes were observed by 

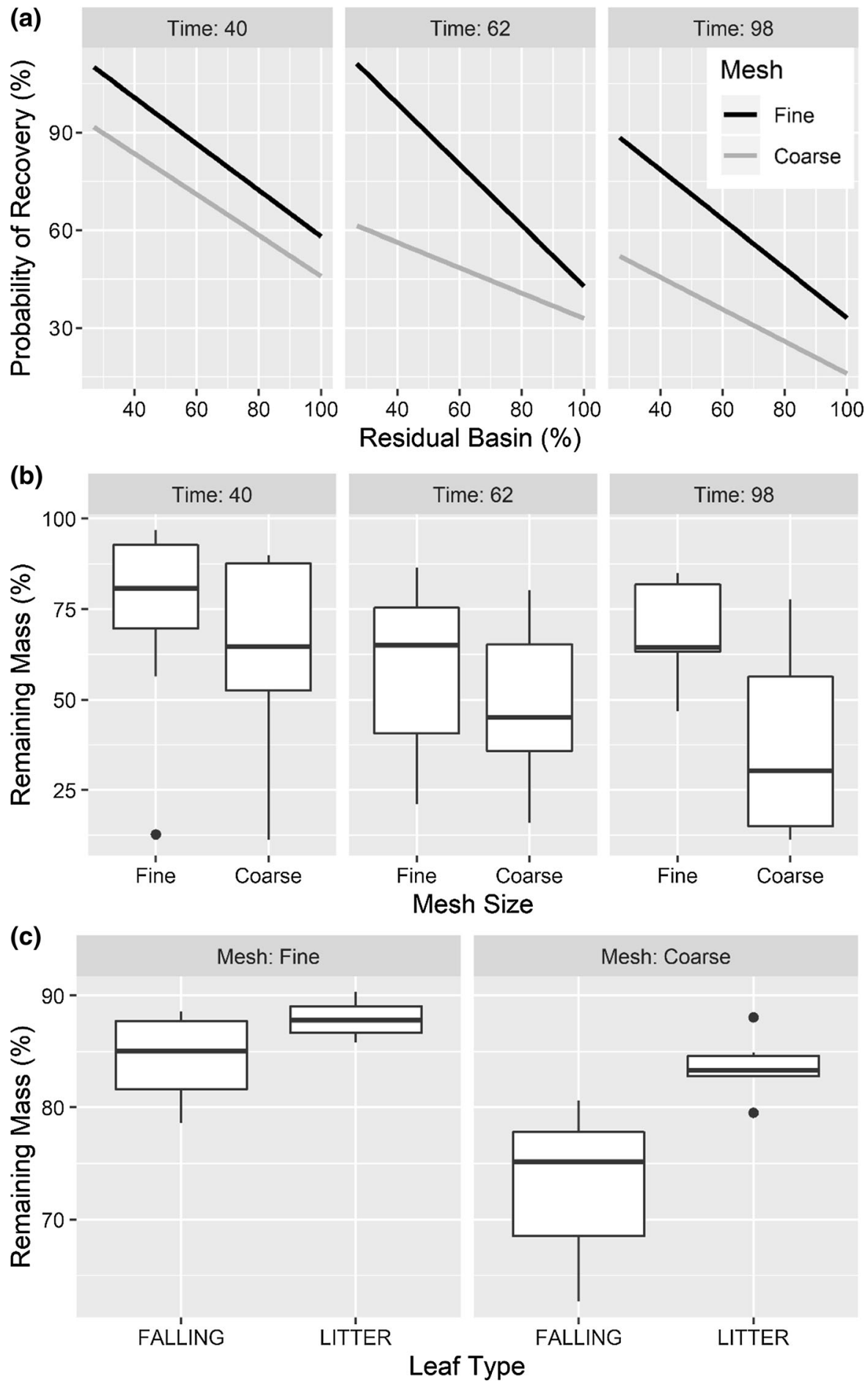

Fig. 4 Graphical representation of the results for the two leaf bags experiments. A probability of recovery for the leaf bags of the summer experiment as a function of residual basin, mesh size, and stay-in-place time ( 5 sites $n=126$ ). B Remaining mass for the leaf bags of the summer experiment as a function of mesh size and stay-in-place time ( 5 sites, $n=69$ ). C Remaining mass for the leaf bags of the winter experiment as a function of mesh size and leaf type ( 2 sites, $n=24)$. All the plots were created using the raw data 


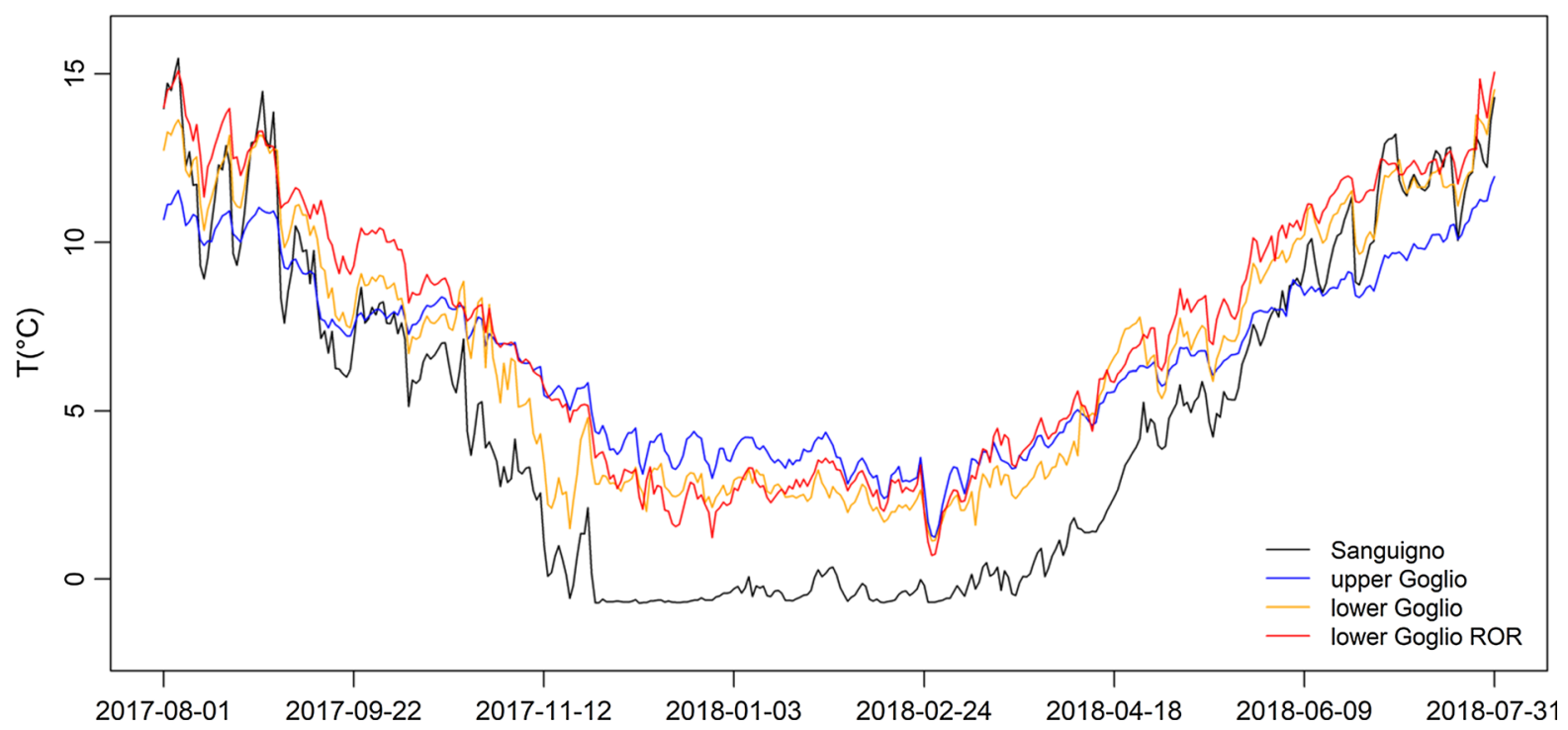

Fig. 5 Mean daily water temperature of Sanguigno (site SAN1-pristine), upper Goglio (site G1—profoundly altered by high-altitude dams), lower Goglio (site G3-partially altered

Brittain \& Saltveit (1989) who suggested that dietary and habitat were the reasons for the observed patterns, as the increase of certain baetids below dams could be linked to greater algal growth (as a food source and predation refuge), while the density of heptageniids that prefer clean rocks for attachment might decrease below dams. Heptageniid abundances in our study decreased in lower Goglio but not in upper Goglio compared to Sanguigno. This suggests that their abundance was driven by pollution loads rather than by alterations of the flow and temperature regimes. This result is consistent with their BMWP (Biological Monitoring Working Party, Armitage et al., 1983) score (10) that classifies them as indicators of good water quality but seems to be less congruent with the LIFE (Lotic-invertebrate Index for Flow Evaluation, Extence et al., 1999) score (I: rapids) as Heptageniidae are also abundant in stretches with altered flow regimes.

Armitage (1978) found that Plecoptera, Trichoptera, and Coleoptera were poorly represented and occurred at low mean densities in a site situated just below the Cow Green dam (River Tees, Upper Teesdale, England) while, a few hundred meters below, Coleoptera (Elmidae) were more abundant. In our study, the response of Plecoptera was not uniform. Perlidae showed the same pattern as Heptagenidaee, while Chloroperlidae were significantly more by high-altitude dams) and lower Goglio with ROR (site G4partially altered by high-altitude dams and by a Run Of the River power plant) in the period August 01, 2017- July 31, 2018

abundant in upper Goglio than in Sanguigno, indicating their preference for a more stable hydrological regime even if they had a high LIFE score (I: rapids). Moreover, many species of Plecoptera are coldstenothermal (Fochetti, 2020) and our results on water temperature clearly show that upper Goglio is, on average, colder than Sanguigno suggesting that Plecoptera abundance was probably affected by the joint effect of hydrological conditions and thermal regime. Leuctridae were significantly more abundant in lower Goglio than in Sanguigno, indicating that their abundance was positively affected by moderate anthropogenic impacts and water pollution. In contrast to Armitage's (1978) and Ward's (1995) results that showed the negative effects of dams on both organic transport and biodiversity, we found that some Trichoptera families (Hydroptilidae, Odontoceridae, Rhyacophilidae, and Sericostomatidae) were significantly more abundant in upper Goglio than in Sanguigno; the high abundance of those families in hydrologically altered stretches had been already reported (Cortes et al., 1998) and may be linked to the synergistic effect of larger food supply and more stable flow, as suggested by Boon (1987). This hypothesis is corroborated by our leaf bags experiment: in upper Goglio, leaf bags were not transported by water flow, thus representing an important source of food for shredders such as those trichopteran 

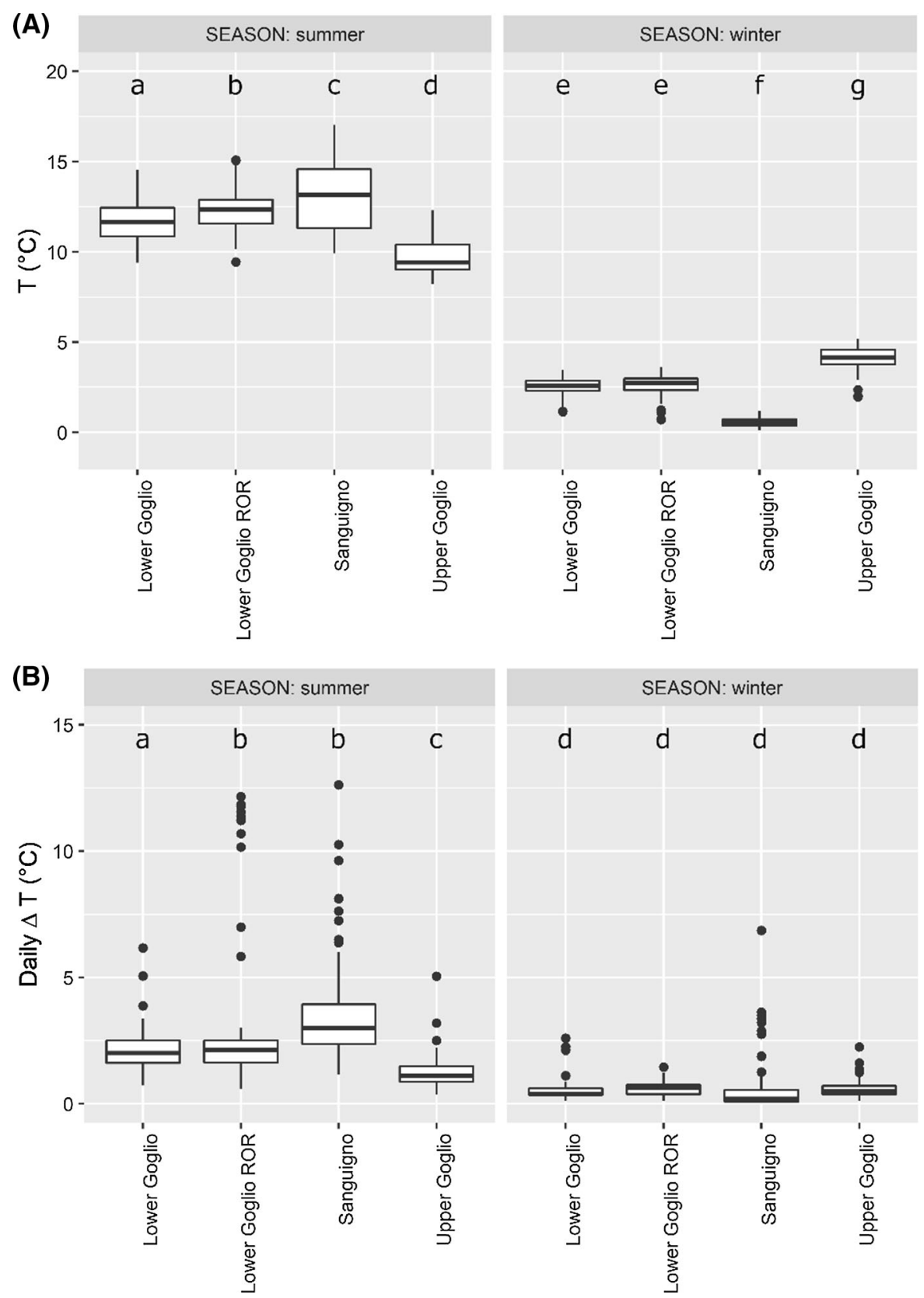

Fig. 6 Box plot presentation of mean daily temperatures (A) and daily temperature variations (B) grouped by stream stretch (Lower Goglio, Lower Goglio ROR, Sanguigno, and

families. Coleoptera (Scirtidae) were more abundant in upper Goglio than in Sanguigno and lower Goglio, suggesting their preference for a more stable hydrological regime, in agreement with their LIFE score (IV: slow and standing waters) and the results of Armitage (1978).
Upper Goglio) and seasons (summer and winter). Different lowercase letters indicate significant differences among categories (Tukey's multiple-comparison test, $P<0.001$ )

The increase of more ubiquitous macroinvertebrate orders including Diptera or Oligochaeta are often reported downstream from impoundments (Ogbeibu \& Oribhabor, 2002; Phillips et al., 2016; Krajenbrink et al., 2019) and this is in agreement with our results as many families belonging to those orders are 
significantly more abundant in upper Goglio than in Sanguigno. Conserving natural landscapes is important not only to preserve species but also to have reference systems that can be studied to understand the pristine state and functioning of ecosystems and correctly evaluate the effect of alteration on other systems (Grill et al., 2019; Milner et al., 2019). This survey shows that conditions in the upper Goglio supported the most diverse macroinvertebrate community compared to other sites, in spite of being profoundly altered by high-altitude reservoirs. Our analysis did not identify any macroinvertebrate family impacted by high-altitude dams due to the coarse systematic resolution (i.e., family level): subfamily level identification of organisms may produce different results in terms of impacts on community and specific genus/species responses (Hotaling et al., 2017). Some authors reported that in high alpine streams, the anthropogenic flow regulation tended to ameliorate stream conditions resulting in higher diversity but this did not favor certain species that are specialist in the harsh natural conditions (Füreder et al., 2000). Although further work is required to address the impact of taxonomic resolution, our results highlights how important is the definition of the reference condition (i.e., expected community composition in pristine sites such as S1 and S2) for bioassessment (Wilding et al., 2018; Fornaroli et al., 2019) and how biomonitoring indices must account for the deviation from the reference condition both as increases or decreases in diversity and abundance of organisms.

\section{Leaf bags experiment}

Statistical analysis for the summer leaf bags experiments shows that the probability of recovery (\%) of leaf bags is significantly influenced by mesh size, time, and residual basin. High-altitude reservoirs partially drain the basin and reduce the water inputs to the Goglio stream. Consequently, the magnitude of flood events was reduced and led to reduced transport of organic matter (i.e., higher probability of recover). Conversely, such differences in flood magnitude did not seem to alter the degradation processes of CPOM, as also observed by Casas et al. (2000) in a Mediterranean stream, giving no support for our $\mathrm{HO}_{1}$ hypothesis.
As the residual basin increases in lower Goglio, the effect of reservoirs on flood events becomes marginal and the flow regime was regulated mainly by the inputs from the tributaries. In these conditions, the magnitude of flood events increased, and this was reflected in a decrease in the probability of recovery of leaf bags, which were more easily removed from the riverbed. This phenomenon was more evident for coarse bags, probably because debris carried by the floods could easily anchor to the meshes and increase the strength exerted by the flowing water. This result suggests that natural leaf packs can follow similar dynamics (Braioni et al., 2001), with comparable breakdown rates but with higher CPOM availability in altered stretches than in pristine one (Martínez et al., 2013), especially during summer when high flow events are more frequent. The probability of recovery was also reduced, especially for coarse mesh bags, by the time spent in water, mostly due to the higher number of high flow events occurred since the positioning of leaf bags.

The remaining mass (\%) of leaf bags was significantly influenced by mesh size and time. Coarse mesh leaf bags showed a lower percentage of residual mass than fine mesh leaf bags because leaves go through the mesh more easily after being smashed by mechanical degradation; furthermore, they give access to larger invertebrates and are potentially subject to higher biological degradation (Graça et al., 2001; Slade \& Riutta, 2012). As the time of exposure of bags to mechanical and biological degradation increases, the $\%$ of remaining mass decreases.

During the summer experiment, different high flow events occurred, while low flow conditions lasted for the whole duration of the winter experiment. The results of the winter experiment highlight that the remaining mass $(\%)$ was significantly affected by the type of leaf: leaf bags filled with falling leaves showed a lower remaining mass than those filled with leaves collected from the litter as previously highlighted by Gessner \& Chauvet( 2002). Probably, the retention of labile carbon and nutrients in fresh leaf litter facilitated their utilization by leaf-associated micro-organisms and invertebrates, and this raised the importance of biotic processes with respect to physical processes such as leaching (Gessner, 1991). Moreover, as for the summer experiment, coarse mesh bags showed higher degradation rate and this was particularly evident for bags filled with falling leaves. Those results confirm 
that both fallen and manually detached leaves are a food source for macroinvertebrates and highlight that CPOM availability is controlled also by the flow regime and not only by its seasonal availability.

\section{Water temperature}

The different thermal regime of the stream stretches is mostly due to the hydrologic regulation, as Goglio is regulated by high-altitude reservoirs while Sanguigno is not. In summer, thermal stratification occurs in reservoirs: in the deeper layers, the water is colder and denser than in the surface ones which are continuously heated by the solar radiation. That's why in upper Goglio, which is fed on water released from the lower layers of reservoirs, water was colder than in Sanguigno due to the reservoir release. This supports the $\mathrm{HT}_{1}$ hypothesis and is in line with other studies (Webb \& Nobilis, 1995; Toffolon et al., 2010). An opposite situation (the reservoir discharge increases water temperature downstream) would occur if the release of water from the reservoirs would take place from the surface or where riverine water is cooler due to strong snow meltwater inputs, as observed by Dickson et al. (2012). In winter, as the lake surface was entirely frozen, the temperature at the bottom was close to $4^{\circ} \mathrm{C}$ so the water temperature downstream was closely linked to the temperature of the hypolimnetic layer. The reservoir release increased the downstream water temperature as described in Céréghino et al. (2002) and Carolli et al. (2008). Reservoirs regulation caused an increase in water temperature, comparable in amplitude to the increase observed by Zolezzi et al. (2011) in the Noce river basin and by Dickson et al. (2012) in the Eisboden catchment (that is $\approx 3^{\circ} \mathrm{C}$ above a lower base temperature). In Sanguigno valley, the winter water temperature dropped even below zero confirming the results of Malard et al. (2006) and Tockner et al. (2010). In the absence of winter snow cover, water temperature records became very similar to air temperature also due to the fact that the flow is naturally at minimum during winter months (Jansson et al., 2003).

The water temperature in lower Goglio (G3) was lower than in upper Goglio (G1) in winter and higher in summer. Those differences were not only due to the mixing of waters from upper Goglio and Sanguigno, but also due to the contribution of the water swirled by the hydropower station and released upstream G3 station. The specific contribution of the swirled water was not determined because the flow data were not available. The summer cooling downstream the hydropower release was consistent with the one measured in the Ticino river, downstream from the Biasca hydropower release (Frutiger, 2004), even if the river size and the discharge flow are very different. Considering the water temperature measured in G4 and G5, the previous elements seem not sufficient to explain a thermal regime much more similar to the one of Sanguigno compared to upper Goglio; otherwise, lower Goglio (G3) and lower Goglio ROR (G4) would be not so different (our $\mathrm{HT}_{3}$ hypothesis), as it has proved by the Tuckey's test. The key driver in this case is represented by the ROR hydropower plants presence. Water temperature depends mostly by the air temperature, but water has a strong thermal inertia due to his high thermal capacity; therefore, larger volume and fast flows reduce the effects of the heat exchanges between water and air. ROR diversions, embezzling water from the stream, reduce the total amount of water and decrease the flow speed so the dependence of water temperature on air dynamics turns out to be strengthened (Brown et al., 2006). For this reason, the daily variability in Sanguigno was not statistically different from the variability in lower Goglio subjected to ROR (G4) but proved to be higher than in the other stretches during summer $\left(\mathrm{HT}_{2}\right)$. However, the drivers that control the thermal regime of rivers regulated from ROR power plants need to be more deeply studied and quantified.

\section{Conclusion}

The presence of hydroelectric power plants (highaltitude reservoirs or ROR plants) modifies the stream ecosystem with regard to all the aspects investigated in this study: macroinvertebrate community composition, organic matter breakdown, and thermal regime.

Macroinvertebrate communities that inhabit pristine sites are generally less diverse than in other sites and more specialized for highly rheophilic environment due to the strong influence of high flow events. In our case study, the stretch subjected to the effect of high-altitude dam showed the best conditions for most of the macroinvertebrate families due to the abundance of food (especially CPOM and dead wood) and the reduced stress due to high flow events. We did not 
identify any family that could be considered representative of undisturbed conditions. The observed lack of representative taxa for undisturbed sites could also be due to the coarse taxonomic resolution (i.e., family level) and subfamily level identification might have produced different specific responses. This would highlight the importance of systematic resolution and the need to develop community-wise metrics that can properly assess this kind of alterations.

Macroinvertebrates communities in the stretch subjected to both hydrological and chemical alterations were characterized by the abundance of families which can tolerate disturbed conditions such as Leuctridae, Limoniidae, and Simuliidae pointing out that, as often reported in literature, alterations due to anthropogenic polluting loads are easier to identify than alterations due to hydrological alterations.

Organic matter availability is positively affected by high-altitude dams. In pristine sites, leaf bags were often removed from the riverbed causing a lower availability of this food source for the macroinvertebrate community. Conversely, the breakdown processes seemed to be only slightly altered by the presence of the high-altitude reservoir as mesh sizes and residence time were the only two factors having a significant effect on breakdown rates. Moreover, our results highlight that the summer input of CPOM to low-order stream can be an important food source, comparable to the winter input of recently fallen leaves. This can be of great importance in pristine sites where the effects of high flow events shorten the residence time of organic matter.

Thermal regime is profoundly altered by highaltitude dams and less influenced by meteorological conditions. The ecological consequences of thermal alterations need to be specifically investigated, especially with mesocosm experiments or ideal case studies that allow to disentangle the effect of thermal and flow regime on biological populations. Those alterations make the stream stretches less subject to the effect of climate change and especially of heat waves that are becoming more and more frequent and intense in the alpine and pre-alpine environments. Reservoirs mitigate the atmospheric influence on stream water temperature while run of the river plants strengthen it in the diverted stretches. Where both these alterations were present, the thermal regime of the stream was more similar to the natural ones compared to stretches subjected to only one kind of alteration and profoundly driven by meteorological conditions.

This research has provided elements for a better understanding of the impact of river impoundments on stream ecosystem structure and functioning. Such elements can be of great use in planning management strategies to protect the environmental quality of watercourses affected by the presence of hydroelectric plants, with particular reference to the growing importance of climate change.

Acknowledgements We are grateful to Simone Invernizzi, Marco Mantovani, Luca Naddeo, Riccardo Cabrini, and Silvia Calabrese for the help in field samplings and to the "Parco delle Orobie Bergamasche" that allowed us to conduct research within the natural protected area.

Funding Open Access funding provided by Università degli Studi di Milano - Bicocca. The authors received no financial support for the research, authorship, or publication of this article.

Data availability The data that support the findings of this study are openly available in "Zenodo" at http://doi.org/10. 5281/zenodo.4294618.

\section{Compliance with ethical standards}

Conflict of interest The authors declare that they have no conflicts of interest.

Open Access This article is licensed under a Creative Commons Attribution 4.0 International License, which permits use, sharing, adaptation, distribution and reproduction in any medium or format, as long as you give appropriate credit to the original author(s) and the source, provide a link to the Creative Commons licence, and indicate if changes were made. The images or other third party material in this article are included in the article's Creative Commons licence, unless indicated otherwise in a credit line to the material. If material is not included in the article's Creative Commons licence and your intended use is not permitted by statutory regulation or exceeds the permitted use, you will need to obtain permission directly from the copyright holder. To view a copy of this licence, visit http://creativecommons.org/licenses/by/4.0/.

\section{References}

Albariño, R. J. \& E. G. Balseiro, 2002. Leaf litter breakdown in Patagonian streams: native versus exotic trees and the effect of invertebrate size. Aquatic Conservation: Marine and Freshwater Ecosystems 12: 181-192.

Allan, R. P., 2012. The role of water vapour in Earth's energy flows. Surveys in Geophysics 33: 557-564.

Anselmetti, F. S., R. Bühler, D. Finger, S. Girardclos, A. Lancini, C. Rellstab \& M. Sturm, 2007. Effects of Alpine 
hydropower dams on particle transport and lacustrine sedimentation. Aquatic Sciences 69: 179-198.

APHA/AWWA/WEF, 2012. Standard Methods for the Examination of Water and Wastewater. Standard Methods 541.

AQEM Consortium, 2002. Manual for the application of the AQEM system. A comprehensive method to assess European streams using benthic macroinvertebrates, developed for the purpose of the Water Framework Directive. Version 1.0 .

Armitage, P. D., 1978. Downstream changes in the composition, numbers and biomass of bottom fauna in the Tees below Cow Green Reservoir and in an unregulated tributary Maize Beck, in the first five years after impoundment. Hydrobiologia 58: 145-156.

Armitage, P. D., D. Moss, J. F. Wright \& M. T. Furse, 1983. The performance of a new biological water quality score system based on macroinvertebrates over a wide range of unpolluted running-water. Water Research 17: 333-347.

Barbour, M. T., J. Gerritsen, B. D. Snyder \& J. B. Stribling, 1999. Rapid Bioassessment Protocols for Use in Streams and Wadeable Rivers: Periphyton, Benthic Macroinertebrates and Fish. Office of Water, U.S. Environmental Protection Agency, Washington, DC.

Bartoń, K., 2019. MuMIn: Multi-Model Inference. R package version 1.43.6. https://CRAN.R-project.org/package= MuMIn.

Bates, D., M. Mächler, B. M. Bolker \& S. C. Walker, 2015. Fitting linear mixed-effects models using lme4. Journal of Statistical Software 67: 1-48.

Bo, T., M. Cammarata, M. J. López-rodríguez, J. M. T. De, S. Fenoglio, J. Manuel, T. D. E. Figueroa \& S. Fenoglio, 2015. Leaf litter decomposition and invertebrate colonization in alpine environments above the tree line: an experimental study. Polish Journal of Ecology 62: 217.

Bocchiola, D., 2014. Long term (1921-2011) hydrological regime of Alpine catchments in Northern Italy. Advances in Water Resources Elsevier Ltd 70: 51-64.

Boon, P. J., 1987. The influence of kielder water on trichopteran (Caddisfly) populations in the river North Tyne (Northern England). Regulated Rivers: Research \& Management 1: 95-109.

Boulton, A. J. \& P. I. Boon, 1991. A review of methodology used to measure leaf litter decomposition in lotie environments: time to turn over an old leaf? Marine and Freshwater Research 42: 1-43.

Braioni, M. G., B. Gumiero \& G. Salmoiraghi, 2001. Leaf bags and natural leaf packs: two approaches to evaluate river functional characteristics. International Review of Hydrobiology 86: 439-451.

Brittain, J. E. \& S. J. Saltveit, 1989. A review of the effect of river regulation on mayflies (Ephemeroptera). Regulated Rivers: Research \& Management 3: 191-204.

Brown, L. E., D. M. Hannah \& A. M. Milner, 2006. Thermal variability and stream flow permanency in an alpine river system. River Research and Applications 22: 493-501.

Brown, L. E., D. M. Hannah \& A. M. Milner, 2007. Vulnerability of alpine stream biodiversity to shrinking glaciers and snowpacks. Global Change Biology 13: 958-966.

Cabrini, R., S. Canobbio, L. Sartori, R. Fornaroli \& V. Mezzanotte, 2013. Leaf packs in impaired streams: the influence of leaf type and environmental gradients on breakdown rate and invertebrate assemblage composition. Water, Air, \& Soil Pollution 224: 1-13.

Carolli, M., B. Maiolini, M. C. Bruno, L. Silveri, \& A. Siviglia, 2008. Thermopeaking in an hydropower impacted Alpine catchment. 4th ECRR Conference on River Restoration 2008: 34.

Carraro, L., E. Bertuzzo, L. Mari, I. Fontes, H. Hartikainen, N. Strepparava, H. Schmidt-Posthaus, T. Wahli, J. Jokela, M. Gatto \& A. Rinaldo, 2017. Integrated field, laboratory, and theoretical study of PKD spread in a Swiss prealpine river. Proceedings of the National Academy of Sciences 114: 11992-11997.

Casas, J. J., C. Zamora-Muñoz, F. Archila \& J. Alba-Tercedor, 2000. The effect of a headwater dam on the use of leaf bags by invertebrate communities. Regulated Rivers: Research \& Management 16: 577-591.

Céréghino, R., P. Cugny \& P. Lavandier, 2002. Influence of intermittent hydropeaking on the longitudinal zonation patterns of benthic invertebrates in a mountain stream. International Review of Hydrobiology 87: 47-60.

Clarke, K. R. \& M. Ainsworth, 1993. A method of linking multivariate community structure to environmental variables. Marine Ecology Progress Series 92: 205-219.

Cortes, R. M. V., M. T. Ferreira, S. V. Oliveira \& F. Godinho, 1998. Contrasting impact of small dams on the macroinvertebrates of two Iberian mountain rivers. Hydrobiologia 389: 51-61.

Danger, A. R. \& B. J. Robson, 2004. The effects of land use on leaf-litter processing by macroinvertebrates in an Australian temperate coastal stream. Aquatic Sciences 66: 296-304.

Dickson, N. E., J. L. Carrivick \& L. E. Brown, 2012. Flow regulation alters alpine river thermal regimes. Journal of Hydrology 464-465: 505-516.

Doretto, A., F. Bona, E. Falasco, D. Morandini, E. Piano \& S. Fenoglio, 2020. Stay with the flow: how macroinvertebrate communities recover during the rewetting phase in Alpine streams affected by an exceptional drought. River Research and Applications 36: 91-101.

Doretto, A., F. Bona, E. Falasco, E. Piano, P. Tizzani \& S. Fenoglio, 2016. Fine sedimentation affects CPOM availability and shredder abundance in Alpine streams. Journal of Freshwater Ecology 31: 299-302.

Extence, C., D. M. Balbi \& R. P. Chadd, 1999. River flow indexing using British benthic macroinvertebrates: a framework for setting hydroecological objectives. Regulated Rivers-Research \& Management 15: 543-574.

Fenoglio, S., T. Bo, M. Cammarata, M. J. López-Rodríguez \& J. M. Tierno De Figueroa, 2015. Seasonal variation of allochthonous and autochthonous energy inputs in an Alpine stream. Journal of Limnology 74: 272-277.

Fochetti, R., 2020. Endemism in the Italian stonefly-fauna (Plecoptera). Zootaxa 4722: 381-388.

Fornaroli, R., S. Calabrese, F. Marazzi, S. Zaupa \& V. Mezzanotte, 2019. The influence of multiple controls on structural and functional characteristics of macroinvertebrate community in a regulated Alpine river. Ecohydrology 12: $1-12$.

Frutiger, A., 2004. Ecological impacts of hydroelectric power production on the River Ticino. Part 2: Effects on the larval development of the dominant benthic macroinvertebrate 
(Allogamus auricollis, Trichoptera). Archiv fur Hydrobiologie 159: 57-75.

Füreder, L., C. Schütz, R. Burger \& M. Wallinger, 2000. Seasonal abundance and community structure of Chironomidae in two contrasting high alpine streams. Internationale Vereinigung für theoretische und angewandte Limnologie: Verhandlungen 27: 1596-1601.

Füreder, L., C. Vacha, K. Amprosi, C. M. E. Hansen \& C. Moritz, 2002. Reference conditions of Alpine streams: physical habitat and ecology. Water, Air and Soil Pollution 2: 275-294.

Gessner, M. \& E. Chauvet, 2002. A case for using litter breakdown to assess functional stream integrity. Ecological applications 12: 498-510.

Gessner, M. O., 1991. Differences in processing dynamics of fresh and dried leaf litter in a stream ecosystem. Freshwater Biology 26: 387-398.

Graça, M. A. S., V. Ferreira, C. Canhoto, A. C. Encalada, F. Guerrero-Bolaño, K. M. Wantzen \& L. Boyero, 2015. A conceptual model of litter breakdown in low order streams. International Review of Hydrobiology 100: 1-12.

Graça, M. S. \& R. C. F. Ferreira, 2001. Litter processing along a stream gradient: the role of invertebrates and decomposers. Journal of the North American Benthological Society 20: 408-420.

GRASS Development Team, 2018. Geographic Resources Analysis Support System (GRASS) Software - Version 7.4.1.

Grill, G., B. Lehner, M. Thieme, B. Geenen, D. Tickner, F. Antonelli, S. Babu, P. Borrelli, L. Cheng, H. Crochetiere, H. E. Macedo, R. Filgueiras, M. Goichot, J. Higgins, Z. Hogan, B. Lip, M. E. McClain, J. Meng, M. Mulligan, C. Nilsson, J. D. Olden, J. J. Opperman, P. Petry, C. R. Liermann, L. Sáenz, S. Salinas-Rodríguez, P. Schelle, R. J. P. Schmitt, J. Snider, F. Tan, K. Tockner, P. H. Valdujo, A. van Soesbergen \& C. Zarfl, 2019. Mapping the world's free-flowing rivers. Nature 569: 215-221.

Hartig, F., 2019. Residual Diagnostics for Hierarchical (MultiLevel / Mixed) Regression Models, R package version 0.2.4, https://CRAN.R-project.org/package=DHARMa.

Hering, D., O. Moog, L. Sandin \& P. F. M. Verdonschot, 2004. Overview and application of the AQEM assessment system. Hydrobiologia 516: 1-20.

Hette-Tronquart, N., J. M. Roussel, B. Dumont, V. Archaimbault, D. Pont, T. Oberdorff \& J. Belliard, 2013. Variability of water temperature may influence food-chain length in temperate streams. Hydrobiologia 718: 159-172.

Hotaling, S., D. S. Finn, J. Joseph Giersch, D. W. Weisrock \& D. Jacobsen, 2017. Climate change and alpine stream biology: progress, challenges, and opportunities for the future. Biological Reviews 92: 2024-2045.

Hotelling, H., 1933. Analysis of a complex of statistical variables into principal components. Journal of Educational Psychology 24: 417-441.

Jansson, P., R. Hock \& T. Schneider, 2003. The concept of glacier storage: a review. Journal of Hydrology 282: 116-129.

Jones, N. E., 2013. Spatial patterns of benthic invertebrates in regulated and natural rivers. River Research and Applications 29: 343-351.
Jordan, S., J. J. Giersch, C. C. Muhlfeld, S. Hotaling, L. Fanning, T. H. Tappenbeck \& G. Luikart, 2016. Loss of genetic diversity and increased subdivision in an endemic alpine stonefly threatened by climate change. PLoS ONE 11: e0159931.

Kassambara, A., \& F. Mundt, 2017. factoextra: Extract and Visualize the Results Multivariate Data Analyses. R package version 1.0.5.

Korner-Nievergelt, F., T. Roth, S. von Felten, J. Guélat, B. Almasi \& P. Korner-Nievergelt, 2015. Bayesian data analysis in ecology using linear models with R, BUGS, and Stan. Elsevier, New York.

Krajenbrink, H. J., M. Acreman, M. J. Dunbar, D. M. Hannah, C. L. R. Laizé \& P. J. Wood, 2019. Macroinvertebrate community responses to river impoundment at multiple spatial scales. Science of the Total Environment The Authors 650: 2648-2656.

Maiolini, B. \& M. Bruno, 2008. The River Continuum Concept Revisited: Lessons from the Alps The Water Balance of the Alps, Alpine Space - Man \& Environment, Vol. 3. Innsbruck University Press, Innsbruck, Austria: 67-76.

Malard, F., U. Uehlinger, R. Zah \& K. Tockner, 2006. Floodpulse and riverscape dynamics in a braided glacial river. Ecology 87: 704-716.

Maloney, D. C. \& G. A. Lamberti, 1995. Rapid decomposition of summer-input leaves in a Northern Michigan Stream. American Midland Naturalist 133: 184-195.

Mantel, S. K., D. A. Hughes \& N. W. J. Muller, 2010. Ecological impacts of small dams on South African rivers part 1: Drivers of change - water quantity and quality. Water SA 36: 351-360.

Martínez, A., A. Larrañaga, A. Basaguren, J. Pérez, C. Mendoza-Lera \& J. Pozo, 2013. Stream regulation by small dams affects benthic macroinvertebrate communities: from structural changes to functional implications. Hydrobiologia 711: 31-42.

McArthur, V. J. \& J. R. Barnes, 1988. Community dynamics of leaf litter breakdown in a Utah Alpine Stream. Journal of the North American Benthological Society 7: 37-43.

McGregor, G., G. E. Petts, A. M. Gurnell \& A. M. Milner, 1995. Sensitivity of alpine stream ecosystems to climate change and human impacts. Aquatic Conservation: Marine and Freshwater Ecosystems 5: 233-247.

Milner, V. S., S. M. Yarnell \& R. A. Peek, 2019. The ecological importance of unregulated tributaries to macroinvertebrate diversity and community composition in a regulated river. Hydrobiologia Springer International Publishing 829: 291-305.

Muhlfeld, C. C., J. J. Giersch, F. R. Hauer, G. T. Pederson, G. Luikart, D. P. Peterson, C. C. Downs \& D. B. Fagre, 2011. Climate change links fate of glaciers and an endemic alpine invertebrate. Climatic Change. 106: 337-345.

Nakagawa, S. \& H. Schielzeth, 2013. A general and simple method for obtaining R2 from generalized linear mixedeffects models. Methods in Ecology and Evolution 4: 133-142.

Nanda, A., T. Asaeda, T. Fujino, K. Siong \& T. Nakajima, 2009. Aggregation of Lepidostomatidae in small mesh size litterbags: implication to the leaf litter decomposition process. Wetlands Ecology and Management 17: 417-421. 
Null, S. E., J. H. Viers, M. L. Deas, S. K. Tanaka \& J. F. Mount, 2013. Stream temperature sensitivity to climate warming in California's Sierra Nevada: impacts to coldwater habitat. Climatic Change 116: 149-170.

Ogbeibu, A. E. \& B. J. Oribhabor, 2002. Ecological impact of river impoundment using benthic macro-invertebrates as indicators. Water Research 36: 2427-2436.

Oksanen, J., F. G. Blanchet, M. Friendly, R. Kindt, P. Legendre, D. Mcglinn, P. R. Minchin, R. B. O'Hara, G. L. Simpson, P. Solymos, M. H. H. Stevens, E. Szoecs, \& E. Wagner, 2017. Vegan: Community Ecology package.

Petts, G. E., 1984. Sedimentation within a regulated river. Earth Surface Processes and Landforms 9: 125-134.

Phillips, I. D., M. S. Pollock \& D. P. Chivers, 2016. Benthic communities through the construction of a major reservoir and 40 years of change. Fundamental and Applied Limnology 188: 279-288.

Piano, E., A. Doretto, E. Falasco, S. Fenoglio, L. Gruppuso, D. Nizzoli, P. Viaroli \& F. Bona, 2019. If Alpine streams run dry: the drought memory of benthic communities. Aquatic Sciences Springer International Publishing 81: 1-14.

Principe, R. E., 2010. Ecological effects of small dams on benthic macroinvertebrate communities of mountain streams (Córdoba, Argentina). Annales de Limnologie 46: 77-91.

QGIS Development Team, 2018. QGIS Geographic Information System - Version 2.18.9.

R Core Team, 2019. R: A Language and Environment for Statistical Computing. R Foundation Statistical Computing, Vienna, Austria.

Schmera, D., J. Heino, J. Podani, T. Erős \& S. Dolédec, 2017. Functional diversity: a review of methodology and current knowledge in freshwater macroinvertebrate research. Hydrobiologia 787: 27-44.

Slade, E. M. \& T. Riutta, 2012. Interacting effects of leaf litter species and macrofauna on decomposition in different litter environments. Basic and Applied Ecology Elsevier GmbH 13: 423-431.

Spänhoff, B., C. Augspurger \& K. Küsel, 2007. Comparing field and laboratory breakdown rates of coarse particulate organic matter: sediment dynamics mask the impacts of dissolved nutrients on CPOM mass loss in streams. Aquatic Sciences 69: 495-502.

Stanford, J. A. \& J. V. Ward, 2001. Revisiting the serial discontinuity concept. Regulated Rivers: Research \& Management 17: 303-310.

Storey, A. W., D. H. Edward \& P. Gazey, 1991. Recovery of aquatic macroinvertebrate assemblages downstream of the Canning Dam, Western Australia. Regulated Rivers: Research \& Management 6: 213-224.

Tockner, K., M. Pusch, D. Borchardt \& M. S. Lorang, 2010. Multiple stressors in coupled river-floodplain ecosystems. Freshwater Biology 55: 135-151.
Toffolon, M., A. Siviglia \& G. Zolezzi, 2010. Thermal wave dynamics in rivers affected by hydropeaking. Water Resources Research 46: 68.

Viganò, G., G. Confortola, R. Fornaroli, R. Cabrini, S. Canobbio, V. Mezzanotte \& D. Bocchiola, 2015. Effects of future climate change on a river habitat in an Italian alpine catchment. Journal of Hydrologic Engeneering American Society of Civil Engineers (ASCE) 21: 1-14.

Voelz, N. J. \& J. V. Ward, 1991. Biotic responses along the recovery gradient of a regulated stream. Canadian Journal of Fisheries and Aquatic Sciences 48: 2477-2490.

Wang, S., H. Ruan \& Y. Han, 2010. Effects of microclimate, litter type, and mesh size on leaf litter decomposition along an elevation gradient in the Wuyi Mountains, China. Ecological Research 25: 1113-1120.

Ward, J. V. \& J. A. Stanford, 1995. The serial discontinuity concept: extending the model to floodplain rivers. Regulated Rivers: Research \& Management 10: 159-168.

Webb, B. W. \& F. Nobilis, 1995. Long term water temperature trends in Austrian rivers. Hydrological Sciences Journal 40: 83-96.

White, J. C., A. House, N. Punchard, D. M. Hannah, N. A. Wilding \& P. J. Wood, 2018. Macroinvertebrate community responses to hydrological controls and groundwater abstraction effects across intermittent and perennial headwater streams. Science of the Total Environment. 610-611: 1514-1526.

Wiejaczka, Ł., M. Kijowska-strugała, P. Pierwola \& M. Nowak, 2018. Water temperature dynamics in a complex of reservoirs and its effect on the temperature patterns of a mountain river. Water Resources 45: 861-872.

Wilding, N. A., J. C. White, R. P. Chadd, A. House \& P. J. Wood, 2018. The influence of flow permanence and drying pattern on macroinvertebrate biomonitoring tools used in the assessment of riverine ecosystems. Ecological Indicators Elsevier 85: 548-555.

Williams, G. P., \& M. G. Wolman, 1984. Downstream effects of dams on alluvial rivers. Geological Survey Professional Paper; 1286. US Geological Survey Professional Paper.

Zolezzi, G., A. Bellin, M. C. Bruno, B. Maiolini \& A. Siviglia, 2009. Assessing hydrological alterations at multiple temporal scales: Adige River, Italy. Water Resources Research 45: $1-15$.

Zolezzi, G., A. Siviglia, M. Toffolon \& B. Maiolini, 2011. Thermopeaking in Alpine streams: event characterization and time scales. Ecohydrology 4: 564-576.

Publisher's Note Springer Nature remains neutral with regard to jurisdictional claims in published maps and institutional affiliations. 